\title{
ANNOUNCEMENT
}

\section{Forthcoming articles}

Visit First View Articles via journals/cambridge.org/lin to access articles prior to print publication.

Liselotte Anderwald

Are non-standard dialects more 'natural' than the standard? A test case from verb morphology

\section{Matthew Baerman}

Defectiveness and homophony avoidance

Thomas Berg

A diachronic frequency account of the allomorphy of some grammatical markers

András Cser

The floating $\mathrm{C}$-place node in Latin

Daniel A. Dinnsen, Christopher R. Green, Judith A. Gierut \& Michele

L. Morrisette

On the anatomy of a chain shift

Cristina D. Dye

Reduced auxiliaries in early child language: Converging observational and experimental evidence from French

M. Teresa Espinal \& Louise McNally

Bare singular nominals and incorporating verbs in Spanish and Catalan

Nicholas Fleisher

Attributive adjectives, infinitival relatives, and the semantics of inappropriateness

Fatima Hamlaoui

On the role of phonology and discourse in Francilian French wh-questions

Ken Hiraiwa

The mechanism of inverted relativization in Japanese: A silent linker and inversion

Terje Lohndal

Freezing effects and objects

Kunio Nishiyama

Conjunctive agreement in Lamaholot 